\title{
Complexity Theory, Nonlinear Dynamics, and Change: Augmenting Systems Theory
}

\author{
Ralph Woehle
}

\begin{abstract}
Social work change processes are addressed in terms of complexity theory and nonlinear dynamics, adding the edge-of-chaos, as well as chaos to the entropy and homeostasis of ecosystems theory. Complexity theory sees the edge-of-chaos as valuable to living systems. A logistic difference equation is utilized to model the nonlinear dynamics of the hypothetical contentment of an individual. The modeling suggests that substantial input would be required to move an individual from homeostasis to the beneficial stage at the edge-of-chaos, but that too much input might result in chaos. With good measurement and data observed over time, social work might benefit from complexity theory and nonlinear dynamics, which are already advancing in related disciplines.
\end{abstract}

Keywords: Complexity, nonlinear, dynamics, systems, chaos

$\mathrm{S}$ ocial workers want to help clients make changes, but they are also concerned with stabilizing client situations. In various social work-related articles in recent years (DeJong, 1995; Warren, Franklin, \& Streeter, 1998; Bolland \& Atherton, 1999; Hudson, 2000a, 2000b; Warren \& Knox, 2000; Warren, Hawkins, \& Sprott, 2003; Halmi, 2003; Hudson, 2004), it has been suggested that complexity theory might add significantly to social work's conceptualization of change, particularly to ecosystems theory. However, since much of the literature pertaining to complexity is of a general conceptual nature, the discussion must be framed in a way that more explicitly addresses social work change processes and describes how social work practice might be informed by complexity approaches to theory and associated nonlinear modeling. I begin that discussion with a review of the development of complexity theory and nonlinear dynamics as they apply to my paper.

\section{COMPLEXITY THEORY AND NONLINEAR DYNAMICS}

Complexity is a theory, with accompanying mathematical models, about the behavior of systems. The term complexity itself refers to the degree of elaboration required for a basic explanation. Complexity theory is related to both ecosystems

Ralph Woehle, Ph.D. is professor at the Department of Social Work, University of North Dakota, Grand Forks, ND 58202-7135.

Copyright $^{\odot} 2007$ Advances in Social Work Vol. 8 No. 1 (Spring 2007) 141-151. 
and chaos theory, all three of which have been used to conceptualize biological, social, and psychological systems. However, to a greater extent than ecosystems theory, complexity theory attempts to explain why systems demonstrate emergent patterns that are greater than the summed effects of the original parts. In addition, complexity theory developed from computing ability, particularly where that ability allowed analysts to suspend strict logic and assumptions to model behavior realistically.

\section{Complexity and the Physical Sciences}

At the beginning of the $20^{\text {th }}$ century, Newton's laws of motion dominated science and described change as predictable. Then, with the theory of relativity and quantum physics, physicists questioned Newton's laws and argued that they were insufficient to describe motion at extreme speeds or for very small particles (Marion, 1999). More recently, Prigogine (1997) has suggested an end of certainty in physics and chemistry in a world that is neither predicted nor arbitrary, but rather at the edge-of-chaos.

A number of authors have written about complexity and nonlinear dynamics, including James Gleick (1987) and Roger Lewin (1992). The history of nonlinear dynamics is the discovery that computers can go beyond mathematical proofs and theoretical assumptions to simulate a much wider array of behavior. Gleick described the computer modeling of weather systems, conducted by Edward Lorenz in the early 1960s, whose nonlinear descriptions went beyond explaining any single particle to new understandings of the larger system. Lorenz's experiments identified attractors in systems that kept the transformation of patterns within a certain range of behavior-a new kind of order.

Lewin (1992) described the invention of the "game of life," by British mathematician Jon Conway, as an early simulation. Others-Steve Wolfram and Chris Langton among them-enhanced that technique to create various models with cellular automata, grids of cells in which each cell operated according to local rules, but global patterns emerged on the grid. Watts' (2003) description of the developments of network dynamics traced those ideas to such physical phenomena as the failure of the electrical power network, as well as to airline networks and their role in the rapid spread of disease. Such dynamics have been explored by computer scientists, physicists, mathematicians, biologists, and engineers.

\section{Complexity and Psychology}

The application of the concepts of complexity and dynamic behavior of variables to psychology is a recent development, but with some older roots. Watts (2003) credits Stanley Milgram with the idea that everyone in the world is just six relationships away from everyone else, Solomon Asch with the idea that our perceptions are dependent on the perceptions of others, and Herbert Simon with the idea of limited or bounded rationality. All three were social scientists from the mid $20^{\text {th }}$ century, and all of the above ideas are important in computer simulations of human behavior.

Butz (1997) was an early advocate of the metaphorical application of chaos in psychoanalytic psychology. Globus (2005) recently summarized the psychody- 
namic view of complexity. He said the brain self-organizes the "belonging together" of thoughts. The process takes place on a landscape where peaks represent repellers (a phobic object for example) and valleys represent the attractor areas where thoughts are likely to settle. The individual both self-organizes the settling process and tunes the landscape, according to Globus.

Fredrickson and Losada (2005) have recently identified several issues of relevance to my paper's emphasis on contentment. They say that affect systems are dynamic, with increasing returns due to positive feedback. Furthermore, they say that affect changes over time, as the various components within the affect system mutually influence one another. They add that this reciprocal causality and feedback within dynamic systems is best modeled with nonlinear equations, because it allows for interactive and bi-directional relations, and dynamic systems that characterize affect are nonlinear, with outcomes that are not always proportional to inputs. Finally, they also point to local unpredictability and global stability. By being variable, individuals are adaptable at the edge-of-chaos. In brief, over time, affect is complex and nonlinear.

Fredrickson and Losada (2005) go on to point out that positive affect broadens thought-action repertoires, whereas negative affect narrows those same repertoires. The variability of positive states over time yields resilience that allows people to adapt flexibly. People who feel positive emotions have a wider array of action urges. Fredrickson and Losada then test the hypothesis that a ratio of positive to negative affect at or above 2.9 will characterize individuals in flourishing mental health and find that it is supported. While I do not wish to make too much of their 2.9 figure, multiples of three do appear to be important in input ratios in complex systems. Finally, Fredrickson and Losada say the literature and their findings suggest that a set of general mathematical principles may describe the relations between positive affect and human flourishing, a conclusion I will embrace.

Watts' (2003) description of the development of network dynamics provided some substance to my assumptions about the environment. As seen below, I assume that all input to an individual's contentment can be addressed with one general variable. Watts' use of Milgram's six degrees and Asch's dependence on the perception of others would help to explain Fredrickson and Losada's (2005) assertions that greater marital happiness is associated with less predictability from moment to moment, as spouses interact and such marriages are more likely to last. Similarly, in business teams, higher levels of expressed positivity among group members have been linked to greater behavioral variability within moment-tomoment interactions as well as to long-range indicators of business success. Positivity and variability do not simply cause success, but positivity molds the environment, while variability tests it, thus promoting mutual adjustment and development of the person and the environment. The social environment is remarkably close, whether it consists of loved ones or strangers, all of whom are within six degrees or less.

\section{Complexity and Social Work}

For social work, the origins of theory regarding systems may be traced to general systems theory (Bertalanffy, 1972), later developed as ecosystems theory. 
Complexity theory surpasses ecosystems theory with conceptions of change. Structure, epiphenomena inferred from observed behavior in systems theory (Dale, Smith, Norlin, \& Chess, 2006), is seen by complexity theory as being in constant change or as process. Complexity theory emerged contemporarily with Wakefield's (1996) criticism of social work's use of ecosystems as unempirical.

Explaining the benefits of change and using mathematical models to describe change processes are the potential contributions of complexity to social work (Hudson, 2000b). Most of the social work articles related to complexity merely suggest that it may be conceptually applicable to understanding social work-related phenomena (Warren, Franklin, \& Streeter, 1998; Hudson, 2000a, 2000b; Halmi, 2003; Hudson, 2004). A few others apply it metaphorically (DeJong, 1995; Bolland \& Atherton, 1999) or actually seek dynamic data patterns (Warren \& Knox, 2000; Warren, Hawkins, \& Sprott, 2003). Thus, the true power of complexity theory and nonlinear dynamics, namely the modeling of practice-like processes, has not been applied in social work.

\section{PURPOSE}

Complexity theory, like its predecessor, ecosystems theory, attempts to be a theory of everything. However, it adds prescriptions for data analysis absent from ecosystems theory. This paper connects that prescription to micro practice, illustrates the applicability of data modeling to highlight change processes, and suggests implications for social work. Specifically, descriptions of change and simple mathematical models are used to construct a hypothetical case regarding a person's contentment. I present comparisons of change processes to suggest ways in which social work interventions could be best implemented to contribute to that advance. While the example used here is psychological, complexity theory is applicable to all levels of systems within which social workers engage. I present a psychological case for simplicity's sake, not with any intention to limit the application of complexity and nonlinear dynamics to microsystems.

\section{PROCESSES INDICATED BY COMPLEXITY THEORY}

The comparison of system functioning is best described across four processes. Ranging from decline to apparent disorder, these four include 1) an entropic/equilibric process, 2) a homeostatic/equilibric process, 3) a complex change process at the-edge-of-chaos, and 4) a chaotic change process. These processes are described in Table 1 and are loosely based on an earlier description of system states and change as described by Anderson and Carter (1990).

Table 1 cross-references the four processes with descriptions of four conditions. These are 1) the condition toward which the process tends, 2) information interchange with the environment, 3) resource interchange with the environment, and 4) change orientation. The first, the condition toward which a psychological system's process tends, consists of patterns of psychological functioning in relation to well being. The next two conditions consider interchange with the environment, referring to both information and resource exchange, where information is the array of signals utilized for guidance, and resources are the commodities needed to fulfill basic needs. Finally, change orientation refers to intention and readiness for change in relation to the environment and the enhancement of functioning. 
Generally, ecosystems and complexity theorists agree that the entropic/equilibric process is the least desirable, because that process might bring pathology or death. Ecosystems theorists see the stability of homeostatic/equilibric processes as desirable (Anderson \& Carter, 1990). Complexity theorists tend to group the stability-oriented entropic/equilibric and homeostatic/equilibric change processes together and see them as undesirable. They see the periodic iterations of complex change processes as particularly valuable and healthy and see the irregular chaotic change process as disruptive, but of occasional value for substantial change.

Each of the change processes can be considered in the context of a person's contentment and are compared across the four conditions listed in Table 1 . In the entropic process, well being is in decline, because the person is unable to convince the larger system to provide needed resources (Krossman \& Bullrich, 1997). In a homeostatic process, the second process in Table 1 , the person is able to maintain parameters of well being by communicating needs and obtaining at least basic resources. As a result, the person is stable if the environment remains stable. However, the complexity theorist would see this person as near equilibrium, and thus in danger of entropy (Krossman \& Bullrich, 1997). The preferred process of the complexity theorist is the edge-of-chaos or complex process. In that process, limited variation of well being is apparent as feedback is utilized. This limited variation and informed effort guides an efficient resource exchange with the environment.

Finally, the chaotic process is overly variable and unpredictable, making complexity theorists cautious. Measures of the person's well being yield erratic values, though they might stabilize in the long run. People in chaotic processes are often demanding resources, but without being informed about the environment's ability to provide resources or even being informed about their own needs in the immediate future. Even though chaos might lead to entropy, there is some chance that the change orientation of a person in chaotic process is potentially capable of settling into improved conditions (Krossman \& Bullrich, 1997).

In brief, a conceptual contribution of complexity theory to social work is the addition of the nearly chaotic (or complex) change process and the chaotic change process to ecosystems theory, and thus a new change orientation. Where the emphasis of ecosystems theory tends to be homeostasis, complexity theory applied to social work would embrace the benefits of change.

\section{MODELING CHANGE WITH NONLINEAR DYNAMICS}

The variation of a measure of a complex system — contentment, in my examplefollows the patterns described in Table 1. Sometimes, the values of the variable decline and sometimes they settle into a homeostatic pattern, whiled the variable values hardly change. However, when the values of input variables are sufficiently high, the outcome variable value can move to the edge-of-chaos. There, the outcome variable fluctuates in balance between a few approximate values in concert with the environment or, when inputs are excessive, the system spins into chaos and undesirable fluctuation. 


\begin{tabular}{|c|c|c|c|c|}
\hline & $\begin{array}{c}\text { Entropic } \\
\text { Functioning }\end{array}$ & $\begin{array}{c}\text { Homoeostatic } \\
\text { Functioning }\end{array}$ & $\begin{array}{l}\text { Near Chaotic } \\
\text { or Complex } \\
\text { Functioning }\end{array}$ & $\begin{array}{l}\text { Chaotic } \\
\text { Functioning } \\
\text { with Possible } \\
\text { Breakthrough } \\
\text { or Collapse }\end{array}$ \\
\hline $\begin{array}{l}\text { Condition } \\
\text { toward } \\
\text { which } \\
\text { the process } \\
\text { Tends }\end{array}$ & $\begin{array}{l}\text { Pathology, } \\
\text { death of } \\
\text { system }\end{array}$ & $\begin{array}{l}\text { Stable, but } \\
\text { pathological }\end{array}$ & $\begin{array}{l}\text { Marginal } \\
\text { but } \\
\text { fluctuating } \\
\text { well-being } \\
\text { capable of } \\
\text { testing } \\
\text { environment }\end{array}$ & $\begin{array}{l}\text { Erratic } \\
\text { fluctuation } \\
\text { between } \\
\text { extremes of } \\
\text { well-being } \\
\text { and pathology }\end{array}$ \\
\hline $\begin{array}{l}\text { Information } \\
\text { Interchange } \\
\text { with } \\
\text { Environment }\end{array}$ & $\begin{array}{l}\text { System has } \\
\text { inadequate } \\
\text { need } \\
\text { communication } \\
\text { to environ- } \\
\text { ment } \\
\text { provides } \\
\text { excessive } \\
\text { damping } \\
\text { feedback }\end{array}$ & $\begin{array}{l}\text { System is } \\
\text { accepting of } \\
\text { reinforcing } \\
\text { feedback } \\
\text { from } \\
\text { environment } \\
\text { but is not } \\
\text { able to justify } \\
\text { demands for } \\
\text { resources } \\
\text { from the } \\
\text { environment }\end{array}$ & $\begin{array}{l}\text { System locates } \\
\text { information for } \\
\text { correlation of } \\
\text { available } \\
\text { resources to } \\
\text { needs, learns } \\
\text { from assess- } \\
\text { ments of self } \\
\text { and environ- } \\
\text { ment }\end{array}$ & $\begin{array}{l}\text { Information } \\
\text { often not } \\
\text { accessed to } \\
\text { fit rapid change } \\
\text { to environment, } \\
\text { or rapid system } \\
\text { change makes } \\
\text { available } \\
\text { information } \\
\text { untimely }\end{array}$ \\
\hline $\begin{array}{l}\text { Resource } \\
\text { Interchange } \\
\text { with } \\
\text { Environment }\end{array}$ & $\begin{array}{l}\text { Inadequate } \\
\text { resource } \\
\text { inputs and } \\
\text { outputs, } \\
\text { unable to } \\
\text { create } \\
\text { environ- } \\
\text { mentally } \\
\text { acceptable } \\
\text { exchange }\end{array}$ & $\begin{array}{l}\text { System is } \\
\text { able to } \\
\text { maintain } \\
\text { resource } \\
\text { exchange } \\
\text { sufficient for } \\
\text { own stability } \\
\text { if environ- } \\
\text { ment is } \\
\text { constant }\end{array}$ & $\begin{array}{l}\text { System } \\
\text { efficiently } \\
\text { obtains } \\
\text { needed } \\
\text { resources, } \\
\text { and dissipates } \\
\text { waste in } \\
\text { concert with } \\
\text { changing } \\
\text { environment }\end{array}$ & $\begin{array}{l}\text { Resource } \\
\text { exchange } \\
\text { often out of } \\
\text { synchronicity } \\
\text { with system's } \\
\text { fit in } \\
\text { environment }\end{array}$ \\
\hline $\begin{array}{l}\text { Change } \\
\text { Orientation }\end{array}$ & $\begin{array}{l}\text { Resists } \\
\text { growth } \\
\text { based on } \\
\text { limited } \\
\text { resources, } \\
\text { inability to } \\
\text { mount } \\
\text { communica- } \\
\text { tion to expand } \\
\text { resources, } \\
\text { accepts } \\
\text { decline }\end{array}$ & $\begin{array}{l}\text { System grows } \\
\text { to a stable } \\
\text { level, but is not } \\
\text { ready for } \\
\text { environmental } \\
\text { change which } \\
\text { may put } \\
\text { system at risk }\end{array}$ & $\begin{array}{l}\text { System is } \\
\text { always ready } \\
\text { for growth and } \\
\text { change with } \\
\text { periodic } \\
\text { variation which } \\
\text { promotes } \\
\text { system } \\
\text { learning and } \\
\text { tests the } \\
\text { environment }\end{array}$ & $\begin{array}{l}\text { Erratic } \\
\text { system may } \\
\text { stumble into } \\
\text { better condition, } \\
\text { but erratic } \\
\text { behavior and } \\
\text { environmental } \\
\text { insensitivity } \\
\text { put it at } \\
\text { constant risk }\end{array}$ \\
\hline
\end{tabular}

The mathematics of complexity is longitudinal, modeling the values of a small number of variables of a single system over time. Often, this includes the past val- 
ues of outcome variables that are used to estimate future values of outcome variables. In the modeling equations used here, input and output are assumed. Some input is feedback generated by the environmental interaction of the values of outcome variables in the immediate past. Some input stimulates the growth of the outcome variable values, while other input dampens its growth. The measure of input is probably a matter of the ratio of growth producing and damping input (Fredrickson \& Losada, 2005). Repeated iterations of the model equations can be called reciprocal causality, because the outcome variables are alternatively independent and dependent. In my example, this means that contentment at one time influences the next, but social work practice, along with other environmental influences, can modify that impact.

A logistic difference equation is utilized to model variables in the present paper, following Kiel and Elliot (1997). This logistic equation has heuristic value, because it provides a simple view of variable change processes and has been introduced in the social work literature (Warren, Franklin, \& Streeter, 1998). However, Fredrickson and Losada (2005) point to the greater modeling sophistication social work should seek.

\section{Measurement}

For considering the nonlinear dynamics of contentment, the generalized contentment scale (Bloom et al., 2003) offers a useful model for the primary variable. This scale was designed to measure problems and, in the original version, would see increasing scores as problems intensify. Individuals scoring in the top $70 \%$ of these scales were assumed to have problems. Because I want to model the growth of contentment in a manner consistent with Fredrickson and Losada's (2005) growth of positive affect, the scoring of the scale has been reversed, and low scores, $0-70$, are assumed to indicate the problem's end, while scores above 70 are assumed to be positive affect. It will be further assumed here that the scale represents the full possible range of the variables for the present analysis.

\section{Modeling Equations}

A common equation modeling nonlinear dynamics to model change is:

$$
\mathrm{X}_{\mathrm{t}+1}=\mathrm{rX} \mathrm{t}\left(1-\mathrm{X}_{\mathrm{t}}\right)
$$

Where $\mathrm{X}=$ the level of contentment, $\mathrm{X}_{\mathrm{t}}=$ outcome variable in prior iteration, $\mathrm{r}=$ the rate of growth accounted for by the intervention combined with other inputs, (1$\left.\mathrm{X}_{\mathrm{t}}\right)=$ the environmental and systemic damping of the effect of $\mathrm{r}$ and $\mathrm{X}_{\mathrm{t}+1}=$ the next iteration of the outcome variable $\mathrm{X}$.

This equation explains the successive values of the variable $X$ over time. In the calculations below, the values of $X$ are represented by decimals to two places, or the proportion of the 100 points awarded on the contentment scale. Table 2 represents these scale scores as whole numbers, with $\mathrm{X}$ as the number of points achieved on the contentment scale and $\underline{r}$ as the rate of input that, when set at 1 or $100 \%$, would tend to keep $\mathrm{X}$ at an unchanging value without considering environmental impact. The reader will note that the equation is structured so that the values of $X_{t}$ approaching the maximum value of $100 \%$ (100 points on the contentment scale) would cause the $\mathrm{rX}_{\mathrm{t}}$ product to be relatively large, while the $1-\mathrm{X}_{\mathrm{t}}$ 
term would approach zero. At a contentment score of 95, for example, a crash to a score of 19 on the next iteration is expected. The converse is true when $X_{t}$ approaches zero. Thus, the equation tends to be self-balancing, encouraging growth when $\mathrm{X}$ is small and damping growth when $\mathrm{X}$ is large. This self-balancing characteristic makes the equation nonlinear, because equal increments of inputs do not yield proportional increases in the outcome variable X. In my contentment example, low levels of contentment would respond to large inputs and move higher, but higher values would be resistant to improvement, because they are already near the top of the scale and because every system and environment is likely to have some damping inputs that impinge upon the growth of contentment (Fredrickson \& Losada, 2005). The inputs that affect contentment in the hypothetical example might be numerous and various, but $r$, or the rate applied to the previous levels of input, might be altered by interventions associated with social work practice.

In the iterations of the basic equation presented above, each time a value of $\mathrm{X}_{\mathrm{t}+1}$ is calculated, it can become the new $\mathrm{X}_{\mathrm{t}}$ for the calculation of the next $\mathrm{X}, \mathrm{X}_{\mathrm{t}+2}$. These iterations allow for the demonstration of reciprocal causality. That is, one can think of $\mathrm{X}$ as influencing itself and the environment, and the environment, in turn, influencing $X$ and itself as one iterates the equation. However, the equation generally loses its modeling ability when $\underline{r}$ exceeds $4(400 \%)$, because, at that point, it will generate unreal values of $X$ less than 0 or greater than $100 \%$, values that are not possible with the 100-point contentment scale assumed in this paper.

\section{ANALYSIS}

With the above discussion, I have laid the basis for hypothetical analysis utilizing the equation stated above. Table 2 presents hypothetical data analysis that allows comparison of the change processes of Table 1 . The observations listed in Table 2 assume that the data would really behave in the way that the logistic difference equations would project. That is, values of the contentment scale are laid out in successive times (values at the various ts) in the cells of Table 2 . These values were produced by iterations of the logistic difference equations programmed into a spreadsheet. Table 2 also compares initial values of the contentment scale before iteration and compares input rates, which would reflect environmental and system inputs. The input rates, which would presumably be manipulated by social work intervention, have been set to $100 \%, 200 \%, 300 \%$, and $400 \%$. The initial value of the contentment scale at $\underline{t}$ is set at 7 , a very low level of contentment. Thus, the first row of the table shows us what would happen to clients if the input rate were left at $100 \%$ and the control condition, where the decline of contentment toward entropy would continue and, in fact, collapse to zero after numerous iterations.

Table 2 shows that one would want to increase the input rate for clients demonstrating low contentment scores and low input. At the $200 \%$ input rate, contentment increases but levels off at 50. This is a homeostatic process and, though it increases the value of the outcome variable, a homeostatic process is unsatisfactory, because it does not offer the advantages of the edge-of-chaos. Arrival at the edge-of-chaos and a complex process are achieved with an input rate of $300 \%$. 


\begin{tabular}{|c|c|c|c|c|c|c|c|c|c|c|c|}
\hline \multicolumn{12}{|c|}{ 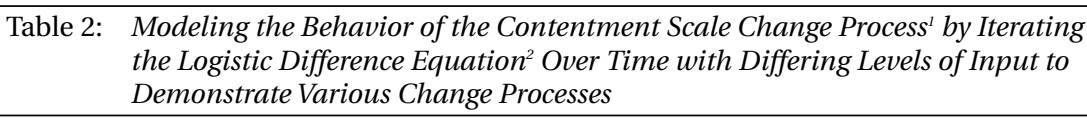 } \\
\hline $\begin{array}{l}\text { Change } \\
\text { Process }\end{array}$ & $\begin{array}{l}\text { Input } \\
\text { Rate }\end{array}$ & $t_{0}$ & $t_{1}$ & $t_{2}$ & $t_{3}$ & $\mathbf{t}_{4}$ & $t_{5}$ & $\mathbf{t}_{6}$ & $t_{7}$ & $\mathbf{t}_{8}$ & $t_{9}$ \\
\hline Entropic & $100 \%$ & 73 & 7 & 6 & 6 & 5 & 5 & 5 & 5 & 4 & 4 \\
\hline Homoeostatic & $200 \%$ & 7 & 13 & 23 & 35 & 46 & 50 & 50 & 50 & 50 & 50 \\
\hline Complex & $300 \%$ & 7 & 20 & 47 & 75 & 57 & 74 & 58 & 73 & 59 & 72 \\
\hline Chaotic & $400 \%$ & 7 & 26 & 77 & 71 & 83 & 57 & 98 & 8 & 29 & 82 \\
\hline \multicolumn{12}{|c|}{$\begin{array}{l}{ }^{1} \text { The } 100 \text { point contentment scale has the lowest contentment at } 1 \text { and the highest contentment at } 100 \text {. } \\
{ }^{2} \mathrm{The} \mathrm{X}_{\mathrm{t}+1}=\mathrm{rX} \mathrm{t}_{\mathrm{t}}\left(1-\mathrm{X}_{\mathrm{t}}\right) \text { logistic difference equation is used to calculate the successive scale values, where th is the } \\
\text { time period. } \\
{ }^{3} \text { Beginning with the low contentment score of } 7 \text { suggests a deeply troubled individual. }\end{array}$} \\
\hline
\end{tabular}

Inspection of the contentment values at $300 \%$ input shows that a periodic pattern of iteration is emerging, and the values of the contentment scale would eventually alternate between 62 and 71 . This range of scores would still be marginally problematic, but the potential of the system at the edge-of-chaos would be positively valued from the complexity viewpoint. Increasing the rate of input to $400 \%$ makes the process chaotic, however. The contentment values of the chaotic change process show no sign of settling down. This shows a danger of excessively high contentment scores and input rates, perhaps leading my individual to carefree, neglectful behavior that brings on discontentment.

\section{DISCUSSION}

This paper has suggested that social work needs the change processes of complexity theory in addition to the entropic and homeostatic processes it has considered in ecosystems theory. It also suggests a new view of client outcomes. Rather than designating variable values at the positive end of the scale as desirable outcomes, the desirable outcome may be characterized by the more modest variable values, with variation that suggests the complex edge-of-chaos readiness for change. Indeed, outcome values that are too high on the scale may bring on risky chaotic conditions. Two qualifications are in order. First, the value of complex processes does not rule out at least the occasional value of the other processes. Entropy resulting in death, chaos resulting in substantial change, or the occasional homeostatic relief from entropy or chaos might have value in some circumstances. Continuing my contentment example, a chaotic trajectory dipping into deep sorrow resulting from a debilitating life experience may result in an ultimate bounce back to contentment, indicating the value of chaos. In addition, the equations used here are no doubt inadequate, therefore social work must do the theory and mathematics to examine fully the potential of complexity theory.

The viability of the theory and mathematical models is ultimately an empirical question (Sabelli et al., 1995), and Fredrickson and Losada (2005) point us in the direction that social work should take. I wish to state strongly that the unempirical 
stance of traditional ecosystems theory (Wakefield, 1996) is unacceptable. Thus, social work must engage complexity theory and nonlinear modeling empirically. Central to the empirical agenda must be the cycling behavior of data over time. People variously cycle through family generational cycles, school years, child developmental stages, and mood swings to name a few. Social work's research, however, is often based on experiments or surveys that are snapshots in time, rather than continuously moving pictures. To examine life's cycles, social work needs a strong program that continues the development of good measurement, and good measures must be applied over time. Nonlinear dynamic modeling can provide the hypotheses with which to test such data.

The potential of complexity theory might be realized then, but not without an ambitious research agenda. Fortunately, social work practice does not need to wait until the research agenda is accomplished. Complexity theory suggests that reasonable people seeking knowledge and action will find order emerging and that the emerging order will be tested in the environment even if our understanding is incomplete (Marion, 1999). Perhaps, practice knowledge will be the key at least some of the time. Scholarship in social work can provide a voice to the environmental test of complexity and can improve understanding by doing the theory, the mathematics, and the data collection. This is a lot to chew on, but social work should come to the complexity table to taste the rich menu it offers.

\section{References}

Anderson, R.E., \& Carter. I. (1990). Human behavior and the social environment: A social systems approach ( $4^{\text {th }}$ ed.). New York: Aldine de Gruyter.

Bloom, M., Fischer, G., \& Orme, J.G. (2003). Evaluating practice: Guidelines for the accountable professional ( $4^{\text {th }}$ ed.). Boston: Allyn \& Bacon.

Bertalanffy, L.V. (1972) The history and status of general systems theory. The Academy of Management Journal, 15(4), 407-426.

Bolland, K., \& Atherton, C.R. (1999). Chaos theory: An alternative approach to social work practice and research. Families in Society: The Journal of Contemporary Human Services, 80(4), 367-373.

Butz, M.R. (1997). Chaos and complexity: Implications for psychological theory and practice. Washington, D.C.: Taylor \& Francis.

Dale, O., Smith, R., Norlin, J., \& Chess, W. (2006). Human behavior and the social environment: Social systems theory ( $5^{\text {th }}$ ed.). Boston: Allyn \& Bacon.

De Jong, J.A. (1995). An approach for high risk prevention research." Drugs and Society, 8(3/4), 125-138.

Fredrickson, B.L., \& Losada, M.F. (2005). Positive affect and the complex dynamics of human flourishing. American Psychologist, 60(7), 678-686.

Gleick, J. (1987). Chaos: Making of a new science. New York: Penguin.

Globus, G. (2005). Nonlinear dynamics at the edge of modernity: A postmodern view. Philosophy, Psychiatry and Psychology, 12(3), 225-234.

Halmi, A. (2003). Chaos and non-linear dynamics: New methodological approaches in the social sciences and social work practice. International Social Work, 46(1), 83-101.

Hudson, C.G. (2000a). From social darwinism to self-organization: Implications for social change theory. Social Service Review, 74(4), 533-559. 
Hudson, C.G. (2000b). At the edge of chaos: A new paradigm for social work? Journal of Social Work Education, 36(2), 215-230.

Hudson, C.G. (2004). The dynamics of self-organization: Neglected dimensions. Journal of Human Behavior in the Social Environment, 10(4), 17-38.

Kiel, D., \& Elliott, E. (1997). Exploring nonlinear dynamics with a spreadsheet: A graphical view for beginners. In D. Kiel \& E. Elliott Eds., Chaos theory in the social sciences: Foundations and applications (pp. 1929). Ann Arbor: University of Michigan Press.

Krossmann, M.R., \& Bullrich, S. (1997). Systematic chaos: Self-organizing systems and the process of change. In F. Masterpasqua \& P.A. Perna. The psychological meaning of chaos: Translating theory into practice (pp. 199-224). Washington, D.C.: American Psychological Association.

Lewin, R. (1992). Complexity: Life at the edge of chaos. New York: Macmillan.

Marion, R. (1999). The edge of organization. Thousand Oaks: Sage.

Prigogine, I. (1997). The end of certainty. New York: The Free Press.

Sabelli, H., Carlson-Sabelli, C.L., Patel, M., Levy, A., \& Diez-Martin, J. (1995). Anger, fear, depression, and crime: Physiological and psychological studies using the process method. In R. Robertson \& A. Combs. Chaos theory in psychology and the life sciences, (pp. 65-88). Mahwah NJ: Lawrence Erlbaum.

Wakefield, J.C. (1996). Does social work need the eco-systems perspective? Is the perspective clinically useful? Social Service Review, 70(1), 1-32.

Warren, K., Franklin, C., \& Streeter, C.L. (1998). New directions in systems theory: Chaos and complexity. Social Work, 43(4), 357-372.

Warren, K., \& Knox, K. (2000). Offense cycles, thresholds and bifurcations: Applying dynamical systems theory to the behaviors of adolescent sex offenders. Journal of Social Service Research, 27(1), 1-27.

Warren, K., Hawkins, R.C., \& Sprott, J.C. (2003). Substance abuse as a dynamical disease: Evidence and clinical implications of nonlinearity in a time series of daily alcohol consumption. Addictive Behaviors, $28,369-374$.

Watts, D. (2003) Six Degrees: The science of the connected age. New York: Norton.

\section{Author's Note:}

Address correspondence to: Ralph Woehle, Ph.D., professor, Department of Social Work, Box 7135, University of North Dakota, Grand Forks, ND, 58202-7135, USA. e-mail: ralphwoehle@mail.und.nodak.edu. 